\title{
Women's greater fear of pain is mediated by neuroticism
}

Courbalay, A.; Deroche, T.; Woodman, Tim

\section{Psychologie Française}

DOI:

10.1016/j.psfr.2015.02.001

Published: 01/06/2016

Peer reviewed version

Cyswllt i'r cyhoeddiad / Link to publication

Dyfyniad o'r fersiwn a gyhoeddwyd / Citation for published version (APA):

Courbalay, A., Deroche, T., \& Woodman, T. (2016). Women's greater fear of pain is mediated by neuroticism. Psychologie Française, 61(2), 153-162. https://doi.org/10.1016/j.psfr.2015.02.001

\footnotetext{
Hawliau Cyffredinol / General rights

Copyright and moral rights for the publications made accessible in the public portal are retained by the authors and/or other copyright owners and it is a condition of accessing publications that users recognise and abide by the legal requirements associated with these rights.

- Users may download and print one copy of any publication from the public portal for the purpose of private study or research.

- You may not further distribute the material or use it for any profit-making activity or commercial gain

- You may freely distribute the URL identifying the publication in the public portal ?
}

Take down policy

If you believe that this document breaches copyright please contact us providing details, and we will remove access to the work immediately and investigate your claim. 
This version of the manuscript was accepted in the Journal Psychologie Française, February 2015

Title: Women's greater fear of pain is mediated by neuroticism

Titre : Les femmes, plus que les hommes ont peur de la douleur : la contribution du névrosisme

Anne Courbalay, Thomas Deroche

University of Paris Sud

Tim Woodman

Bangor University 


\section{Abstract}

Fear of pain is an emotional state linked to a host of negative events, including exaggerated pain perception, distress, and chronic pain. Although many studies have shown that women experience fear of pain more than men do, little is known about the factors that might explain these sex differences. According to an individual-difference approach, it seems valuable to examine the contribution of personality factors, which are considered as major antecedents of cognitions and emotions, including fear. The present study focuses on the potential mediating role of neuroticism - and its six specific facets - in the sex-fear of pain relationship for fear of severe pain, fear of minor pain, and fear of medical pain. Given that neuroticism is greater in women and that this personality trait contributes to the fear of pain, we hypothesized that neuroticism would mediate the sex-fear of pain relationship. Due to the previously established link between experience of pain and the fear of pain, we controlled for the previous experience of pain in the mediation model. Participants ( $n=133$ women; 96 men) completed measures of previous experiences of pain, neuroticism, and fear of pain. Using Preacher and Hayes' SPSS script, we used a bootstrapping method with $n=5000$ bootstrap resamples to test the model. Bootstrapped mediation analyses revealed that neuroticism significantly (within a 95\% confidence interval) mediated the sex-fear of severe pain relationship. Working within a $90 \%$ confidence interval, neuroticism also significantly mediated the sex-fear of pain relationship for fear of minor pain and fear of medical pain. Although the global trait of neuroticism contributed to sex differences in fear of minor pain, it was specifically the neuroticism facet of anxiety that mediated the relationship between sex and fear of severe pain and sex and fear of medical pain. The results suggest that women experience more fear of pain partly because they are more neurotic than men and provide the first evidence that neuroticism in an integral part of the process that differentiates the sexes in fear of pain. Given that the proportion of variance 
accounted for in each of the mediation models ( $8 \%$ at most), there is a clear need for further research to elucidate more fully the mechanisms that underlie sex differences in the fear of pain.

\section{Résumé}

La peur de la douleur est un état émotionnel maladaptatif de réaction à la douleur. Bien que différentes études montrent que les femmes ont davantage peur de la douleur que les hommes, les facteurs qui expliquent cette différence restent à préciser. A travers une approche centrée sur les différences interindividuelles, cette étude a pour objectif de tester le rôle médiateur du névrosisme et de ses facettes dans les relations liant respectivement sexe et peur des douleurs sévères, mineures, médicales. 229 personnes ont complété un recueil de questionnaires mesurant la peur de la douleur, le névrosisme, et les expériences passées avec la douleur (i.e., variable contrôle). Les analyses démontrent que le névrosisme médie la relation entre le sexe et la peur des douleurs sévères. Une tendance similaire est observée pour la peur des douleurs mineures et médicales. Ces résultats confirment l'influence de la personnalité dans les réponses interindividuelles à la douleur.

Mots clés : peur de la douleur, personnalité, névrosisme, différences sexuées, anxiété

Keywords: fear of pain, personality, neuroticism, sex differences, anxiety 
Women's greater fear of pain is mediated by neuroticism

\section{Introduction}

The fear of pain - defined as fearful beliefs that pain represents damage or significant harm to the body - is thought to be more disabling than pain itself (Crombez, Vlaeyen, Heuts, \& Lysens, 1999). Indeed, when pain is experienced with low fear, patients are likely to deal with the pain and to maintain engagement in daily activities, through which functional recovery is promoted. In contrast, when the experience of pain is feared, dysfunctional interpretations give rise to associated safety seeking behaviors such as avoidance/escape and hypervigilance, which can lead to chronic pain, disability, disuse, and depression (Leeuw et al., 2007; Vlaeyen \& Linton, 2002). Although models of pain behaviors (e.g., Vlaeyen \& Linton, 2000) outline the crucial role of fear of pain for understanding chronic pain and provide an account of how such fear develops (Leeuw et al., 2007), these models do not account for any sex differences. Sex differences, however, are prevalent in the literature on fear of pain (Albaret, Muñoz Sastre, Cottencin, \& Mullet, 2004; Horn, Alappattu, Gay, \& Bishop, 2014; Osman, Breitenstein, Barrios, Gutierrez, \& Kopper, 2002).

The purpose of the present study is thus to understand the mechanism that might underlie sex differences in the fear of pain. Specifically, the present research focuses on the potential role of neuroticism as a proximal antecedent of fear of pain that mediates the sex-fear of pain relationship.

When in pain, men and women do not react in the same way. A body of literature indicates that women, compared to men, have significantly lower pain thresholds and tolerance levels (Berkley, 1997; Fillingim, 2003). Women are more likely to report more intense and more frequent experiences of clinical pain, including tension, migraines, or musculoskeletal pain. Researchers have proposed numerous explanations for such sex differences. While most of 
these explanations are biological, genetic, and hormonal (Aloisi, Ceccarelli, Fiorenzani, \& Bonezzi, 2009; Holdcroft \& Berkley, 2005), it is becoming increasingly clear that psychological factors also account for women's generally lower tolerance to pain. Indeed, research has revealed that women report a greater fear of severe pain and medical pain than men do (Albaret, Muñoz Sastre, Cottencin, \& Mullet, 2004). Moreover, an experimental pain study that used electrical stimuli also demonstrated that women reported higher fear of pain (Meulders, Vansteenwegen, \& Vlaeyen, 2012). Given that fear of (severe) pain is experienced particularly by women and leads to a maladaptive response to pain, the identification of the potential mediating factors of the relationship between sex and fear of pain clearly warrants research attention.

Over the past two decades a consensus has emerged that individual traits are thought to constitute relatively stable patterns of cognitions, behaviors, and emotions, including fear (Fleeson, 2001; Kokkonen \& Pulkkinen, 2001; McCrae et al., 2000; Pytlik Zillig, Hemenover, \& Dienstbier, 2002; Sorić, Penezić, \& Burić, 2013). In the specific context of fear of pain, neuroticism appears particularly worthy of investigation. According to most authors (e.g., Costa \& McCrae, 1992; DeYoung \& Gray, 2009), neuroticism reflects a sensitivity to threat and to a range of negative emotions and cognitions that accompany experiences of threat and punishment, including anxiety, depression, anger, irritation, and self-consciousness. In addition, various brain systems associated with reactions to threat have been linked to neuroticism (for a review, see DeYoung \& Gray, 2009). Neuroticism contrasts with emotional stability and even-temperedness (Goldberg, 1992; John \& Srivastava, 1999) and has been shown to predict fear of movement and (re)injury, which is thought to be due to fear lowering the threshold at which pain is perceived as threatening (Goubert, Crombez, \& Van Damme, 2004). This finding was corroborated by Kumari et al. (2007) who reported that neuroticism 
was correlated positively with fear of electric shock. There is thus a reasonably wellestablished link between neuroticism and fear of pain. According to the Big Five theory, neuroticism presents six facets: anxiety, anger/hostility, depression, self-consciousness, impulsiveness, and vulnerability. Of these facets, it is anxiety that is most closely linked to fear. As such, it is likely that neuroticism-associated fear of pain will be most closely linked to the neuroticism facet of anxiety (Keogh \& Asmundson, 2004). Fear is the emotional reaction to a specific, identifiable and immediate threat, such as a dangerous animal or an injury (Rachman, 1998), whereas anxiety is conceived as the general, stable, and trait-like tendency to view the world in a negative way and to respond fearfully to a broad range of situations (Lilienfeld, Turner, \& Jacob, 1993).

There are also well-established sex differences in neuroticism with women scoring higher than men (Costa, Terracciano, \& McCrae, 2001; Vecchione, Alessandri, Barbaranelli, \& Caprara, 2012). The aforementioned links between sex, neuroticism and fear of pain suggest that neuroticism should mediate the sex-fear of pain relationship but such a mediation model has not been tested or reported in the literature.

The main purpose of the current study was to test the hypothesis that neuroticism would mediate the difference between women and men in the fear of pain. We hypothesized that women would experience more fear of (severe) pain than men partly because they are more neurotic. Given the close links between fear, anxiety, and sex, it was expected that the specific neuroticism facet of anxiety would explain the neuroticism-derived sex differences in fear of pain.

As fear of pain is an emotional state influenced by previous experiences with pain (Albaret et al., 2004), we tested these mediating hypotheses when controlling for previous experiences with pain. 


\section{Method}

\subsection{Participants and procedure}

Two hundred twenty seven French participants (94 men and 133 women; Mage $=23.47$ years, $\mathrm{SD}=3.37$, age range $=18-35$ ) took part in the study. At the time of recruitment, we told participants that we were interested in learning more about the different perceptions that people have about themselves. Given the cross-cultural characteristics of personality traits (McCrae \& Terracciano, 2005), we asked for no additional information regarding participants' religion, ethnicity, etc. Participants provided written informed consent after we had assured them that all data would be treated anonymously. All participants were unpaid volunteers.

\subsection{Measures}

Fear of pain. The French version of the 15-item Fear of Pain Questionnaire (Albaret et al., 2004) measures fear of pain on three subscales, each composed of five items: fear of severe pain (e g., breaking your arm), fear of minor pain (e.g., having sand in your eyes), and fear of medical pain (e.g., receiving an injection in your mouth). Participants rated their fear of pain on each subscale using an 11-point Likert scale ranging from 0 (no fear at all) to 10 (extreme fear of pain). Cronbach alphas for each of the three subscales in the present study were good: $\alpha=0.86$ for both of fear of severe pain and fear of medical pain, and $\alpha=0.81$ for fear of minor pain. In accordance with Albaret et al.'s procedure, participants were then instructed to circle all the painful situations that they had experienced. For each subscale, the sum of these experiences was taken as the score of painful situations already experienced.

Neuroticism. The French version of the NEO-PI-R (Rolland, Parker, \& Stumpf, 1998) was used to measure neuroticism through its six facets of anxiety, angry hostility, depression, selfconsciousness, impulsiveness, vulnerability. Participants rated their agreement with 48 short 
sentences (e.g., I am not a particularly worrisome person) on a scale of 0 (strongly disagree) to 4 (strongly agree). Cronbach's alpha was $\alpha=0.90$ for the global trait of neuroticism. Cronbach's alphas for the neuroticism facets were $\alpha=0.80$ for anxiety, $\alpha=0.68$ for angry/hostility, $\alpha=0.70$ for depression, $\alpha=0.60$ for self-consciousness, $\alpha=.61$ for impulsiveness, and $\alpha=0.80$ vulnerability. Although some of these facet alpha coefficients are below recommended thresholds, we proceeded with the facet-level analysis on the basis that the facet-level hypothesis specifically regarded anxiety, for which the alpha was acceptable. Sex and age were reported on questionnaires.

\subsection{Data Analysis}

Using Preacher and Hayes' (2008) SPSS script, a bootstrapping method with $n=5000$ bootstrap resamples, single mediator models were run for exploring the mediational role of neuroticism in the relationship between sex and each subscale of fear of pain. Bootstrapping is a non-parametric resampling procedure that involves repeatedly sampling from the data set and estimating the indirect effects in each resampled data set. Bootstrapping provides a more accurate estimate of the indirect effect with small-to-moderate sample sizes compared to Baron and Kenny's (1986) causal steps criteria or the Sobel tests (Preacher \& Hayes, 2008). For all the models tested, age and previous experiences of pain were controlled.

\section{Results}

\subsection{Preliminary analysis}

Means, $t$-tests results and Pearson correlations are presented in Table 1.

Compared to men, women reported higher neuroticism $(t(225)=5.87, p<.05)$, greater fear of severe pain $(t(225)=3.01, p<.05)$, greater fear of minor pain $(t(225)=2.42, p<.05)$, and greater fear of medical pain $(t(225)=2.77, p<.05)$. In addition, women scored higher than men on all facets of neuroticism $(t s>2,75, p<.01)$ except impulsiveness $(t=.60, p>$ 
.05). There was a significant relationship between neuroticism and fear of severe pain $(r=$ $.25, p<.05)$, fear of minor pain $(r=.16, p<.05)$, and fear of medical pain $(r=.18, p<.05)$. (Insert Table I here).

\subsection{Mediating role of neuroticism}

The bootstrap results indicated that the total contribution of sex on fear of severe pain was significant $(B=.74, S E=.28, p<.05$, see Figure 1$)$, and became statistically insignificant when neuroticism was included in the model $(B=.43, S E=.29, p=.14)$. The mediating effect was significant (point estimates for total indirect effect $=.31 ; 95 \% \mathrm{CI}=.11-.57$ ). In order to examine specifically the facets of neuroticism that were contributing most to the mediation model, we ran a mediation model with the six facets of neuroticism as mediators. The bootstrap results indicated that the total contribution of sex on fear of severe pain was significant $(B=.74, S E=.28, p<.05)$, and became statistically insignificant when the separate facets of neuroticism were included in the model $(B=.22, S E=.29, p=.46)$. However, only anxiety contributed significantly to the mediating model regarding the relationship between sex and fear of severe pain (see Table 2).

The bootstrap results also revealed that the total contribution of sex on fear of minor pain $(B=$ $.52, S E=.22, p<.05)$ and medical pain $(B=.86, S E=.32, p<.05)$ were significant $(B=.72$, $S E=.28, p<.05)$, and became statistically insignificant when neuroticism was included in the models, $B=.38, S E=.23, p=.10, B=.61, S E=.34, p=.08$, respectively. The fear of minor pain mediation analysis (point estimates for total indirect effect $=.14,95 \% \mathrm{CI}=-.01-.33$ ) and fear of medical pain mediation analysis (point estimates for total indirect effect $=.24$; $95 \% \mathrm{CI}=-.01, .54)$ were each marginally short of statistically confirming the fear of severe pain mediation model when using $95 \%$ confidence intervals. Given how close these mediation models were to being statistically significant with $95 \%$ confidence intervals, we re-ran the 
bootstrap analysis with a $90 \%$ confidence interval, which confirmed neuroticism as a mediator of the relationship between sex and fear of minor pain (point estimates for total indirect effect $=.14 ; 90 \% \mathrm{CI}=.02-.29$ ) and fear of medical pain (point estimates for total indirect effect $=$ $.24 ; 90 \% \mathrm{CI}=.05-.49$ ) (see Figure 2 and Figure 3). In order to examine specifically the facets of neuroticism that were contributing most to the mediation models, we re-ran mediation models with the six facets of neuroticism as mediators. No specific facet of neuroticism contributed significantly to the relationship between sex and fear of minor pain whereas anxiety contributed to the mediating model regarding the relationship between sex and fear of medical pain (see Table 3). There was also a specific direct effect of previous experience of minor pain on fear of minor pain $(B=-2.07, S E=.97, p<.05)$, and a specific direct effect of previous experience of medical pain on fear of medical pain $(B=-1.70, S E=$ $.77, p<.05)$.

(Insert Figure 1, Figure 2, and Figure 3 here).

\section{Discussion}

Although existing models of pain behavior (e.g., Vlaeyen \& Linton, 2000) emphasize the crucial role of fear of pain in the occurrence of chronic pain syndrome, they do not provide an account of why this emotional response is experienced more by women. Drawing upon an individual difference approach, the present study tested the hypothesis that neuroticism would mediate the sex-fear of pain relationship.

Our findings provided support for this mediation model; in other words, women experienced more fear of pain partly because they were more neurotic than men. Of particular interest, the more fine-grained additional analyses revealed that despite significant differences between the sexes on the different facets of neuroticism it was specifically the facet of anxiety that mediated the sex-fear of severe and medical pain relationship. This result is coherent, both 
theoretically and empirically, especially given studies that have revealed strong links between fear of pain and anxiety (Keogh \& Asmundson, 2004; Norton \& Asmundson, 2003), and between sex and anxiety (Craske, 2003). The results also corroborate previous studies, in which it has been suggested that trait anxiety is a distal antecedent of fear of pain, which further predicts injury and sensitivity to illness; for example, catastrophic fearfulness of getting injured or becoming seriously ill (Reiss, 1991; Taylor, 1993; Vancleef et al., 2006). Nevertheless, although neuroticism contributed to the relationship between sex and fear of minor pain, this relationship was not explained uniquely by anxiety, which suggests that there might be differences between the mechanism that underlie different types of fear of pain. Furthermore, several studies have revealed that a greater percentage of chronic pain sufferers are women (Berkley, 1997; Racine et al., 2012; Riley, Robinson, Wise, Myers, \& Fillingim, 1998). Nonetheless, to our knowledge no study has previously examined how the negative influence of neuroticism could be linked to such sex differences, and might thus explain women's propensity to experience maladaptive pain. The findings of the present study suggest that further studies would benefit from considerations of a more integrated model of (chronic) pain, which could offer a better understanding of the occurrence of pain syndromes that are predominantly experienced by women (e.g., fibromyalgia, Fietta, 2004). By placing neuroticism at the root of the fear of pain process, these results offer some potential implications in pain management for medical care providers. According to the fear avoidance model (Vlaeyen \& Linton, 2000), when acute pain is perceived as non-threatening, patients are likely to maintain engagement in daily activities, through which functional recovery is promoted (Leeuw et al., 2007, Vlaeyen \& Linton, 2000). In contrast, a vicious circle may be initiated when the pain is catastrophically interpreted (i.e., when pain is magnified, experienced with helplessness and rumination; Sullivan, Bishop, \& Pivik, 1995). 
These dysfunctional interpretations give rise to pain-related fear and associated safety seeking behaviors, such as avoidance/escape and hypervigilance, which worsen the problem in the case of long-lasting pain. Given that neuroticism contributes to the fear of pain and mediates the relationship between sex and fear of pain, it would be interesting for health care practitioners to probe more specifically the question of anxiety in patients suffering (acute or chronic) pain. Such an approach, also advocated by Leeuw and al. (2007), could inform clinicians about their patients' susceptibility to developing and dealing with chronic pain. Consequently, practitioners could potentially add preventative elements to their treatment, such as educating patients about the fear of pain and pain itself (De Peuter, de Jong, Crombez, \& Vlaeyen, 2009), which should help to prevent the fear of pain from developing further. Interestingly, the analyses also revealed that previous experiences with minor and medical pain contributed negatively to fear of pain; that is, the more people experience minor and medical pain, the less they seem to fear such pain. These results could be due to the pain from medical procedures usually being moderate. As such, the fear of minor or medical pain may be more the fear of any associated procedure rather than the fear of pain itself (Muñoz Sastre, Albaret, Maria Reich Escursell, \& Mullet, 2006). Also, any experience of medical procedures as well as the experience of minor pain may make the individual rather more robust to the experience of pain. In other words, individuals who have had experience of medical pain and any associated medical intervention would likely develop an experience with pain that is rather more real than imagined; furthermore, they might build up coping strategies (e.g., specific self-efficacy or perceived control) to deal with these pain such that they experience less fear (Rokke, Fleming-Ficek, Siemens, \& Hegstad, 2004; Tan, Jensen, Robinson-Whelen, Thornby, \& Monga, 2002). Nonetheless, it is important to note that the men in our sample experienced more severe pain than did the women. In the questionnaire that was administered 
to the participants, the five items relating to the fear of severe pain referred to pain invoked by injuries (e.g., breaking a leg, breaking an arm, receiving stitches, being burnt). Of interest, two studies have revealed sex differences in the epidemiology of non-fatal injuries in children, with boys experiencing more injuries than girls overall (Molcho et al., 2006; Scheidt et al., 1995). These results could explain why in the studied sample, men experienced more severe pain than women did. Although previous experiences with pain were not the topic of this study, the results confirm that life events are particularly worthy of attention in the understanding of the mechanism that underlies the fear of minor pain and medical pain (Albaret et al., 2004).

Even though we examined sex differences in fear of pain through a personality based approach, one could also consider these differences through a cultural based approach (Bernardes, Keogh, \& Lima, 2008). That is, in contrast to sex, gender refers to the socially and culturally constructed meaning of being and acting like a man (e.g., tendency to focus on the self, orientation towards active performances, being independent, self-reliant) or a woman (e.g., selflessness, tendency to focus on others' needs, desire to establish emotionally significant connections with others) in occidental societies and may elucidate the interplay between sex, personality and fear of (minor) pain (Bem, 1977; Deaux \& Kite, 1993). Indeed, gender interacts with biological factors such as sex hormones, genetics, immune responses (e.g., Kiecolt-Glaser, McGuire, Robles, \& Glaser, 2002). Conversely, research has already indicated that inter-personal (spousal) interactions affect both immune functions and painbehaviours in a sex-specific manner (e.g., Kiecolt-Glaser et al., 2002; Smith, Keefe, Caldwell, Romano, \& Baucom, 2004). Although previous studies suggest that gender may explain sex differences in pain experience (Sanford, Kersh, Thorn, Rich, \& Ward, 2002), no research attention has yet been given to the role of gender (as opposed to sex) in the fear of pain. The 
interplay between gender, sex, personality, and fear of pain certainly deserves research attention.

The contribution of the study notwithstanding, there are some limitations that should be considered when interpreting the results and considering future research. First, the crosssectional design precludes drawing causal inferences regarding the relationships, particularly with respect to the mediation analyses. However, although we cannot be certain of the direction of these relationships, there are reasons to believe that the causal chain runs from personality to fear of pain as hypothesized. Indeed, personality traits are recognized as major antecedents of cognition and emotion (e.g., Sorić et al., 2013). Second, the proportion of variance accounted for by each mediation model was $8 \%$ at most. Given the importance of neuroticism in the experience of pain, these results indicate that the understanding of the factors and processes that drive fear of pain are far from complete and have yet to be fully elucidated.

\section{Conclusion}

This study is the first to investigate neuroticism as a determinant of sex differences in fear of pain. Results revealed that neuroticism - specifically anxiety -mediates the relationship between sex and fear of (severe, minor, and medical) pain. These findings provide a first step in understanding the mechanisms that underlie the fear of pain and any sex differences therein. The results also have applied implications for health care practitioners regarding the consideration of neuroticism in chronic pain diseases that are particularly experienced by women. Given the modest percentage of variance explained by the mediation models, there remains a need to investigate other variables that could also explain these pain related sex differences. The role of gender, as opposed to sex, would be worth exploring in this regard. 


\section{References}

Albaret, M.-C., Muñoz Sastre, M. T., Cottencin, A., \& Mullet, E. (2004). The Fear of Pain questionnaire: factor structure in samples of young, middle-aged and elderly European people. European Journal of Pain (London, England), 8(3), 273-281.

Aloisi, A. M., Ceccarelli, I., Fiorenzani, P., \& Bonezzi, C. (2009). Les différences hommesfemmes dans la perception et la modulation de la douleur. Douleur et Analgésie, 22(3), $140-145$.

Berkley, K. J. (1997). Sex differences in pain. Behavioral and Brain Sciences, 20(3), 371380.

Bernardes, S. F., Keogh, E., \& Lima, M. L. (2008). Bridging the gap between pain and gender research: a selective literature review. European Journal of Pain, 12(4), 427-440.

Costa, P. T., \& McCrae, R. R. (1992). Revised NEO Personality lnventory (NEO-PI-R) and NEO Five-Factor Inventory (NEO-FFI) professional manual. Odessa FL :

Psychological Assessment Resources.

Costa, P. T., Terracciano, A, \& McCrae, R. R. (2001). Gender differences in personality traits across cultures: robust and surprising findings. Journal of Personality and Social Psychology, 81(2), 322-331.

Craske, M. G. (2003). Origins of Phobias and Anxiety Disorders: Why More Women than Men?. Oxford England : Elsevier.

Crombez, G., Vlaeyen, J. W., Heuts, P. H., \& Lysens, R. (1999). Pain-related fear is more disabling than pain itself: evidence on the role of pain-related fear in chronic back pain disability. Pain, 80(1-2), 329-339. 
Deaux, K., \& Kite, E. (1993). Gender stereotypes. In Denmark, F. \& Paludi, M. (Eds.), Handbook on the psychology of women (pp. 107-139). Westport, CT : Greenwood Press.

De Peuter, S., de Jong, J., Crombez, G., \& Vlaeyen, J. W. S. (2009). The Nature and Treatment of Pain-Related Fear in Chronic Musculoskeletal Pain. Journal of Cognitive Psychotherapy, 23(1), 85-103.

DeYoung, C. G., \& Gray, J. (2009). Personality neuroscience: Explaining individual differences in affect, behavior, and cognition. In Corr, P. \& Matthews, G. (Eds.), The Cambridge handbook of personality psychology (pp. 323-346). New York : Cambridge University Press.

Fillingim, R. B. (2003). Sex-related influences on pain: A review of mechanisms and clinical implications. Rehabilitation Psychology, 48(3), 165-174.

Fleeson, W. (2001). Toward a structure- and process-integrated view of personality: Traits as density distributions of states. Journal of Personality and Social Psychology, 80(6), $1011-1027$.

Goldberg, L. R. (1992). The development of markers for the Big-Five factor structure. Psychological Assessment, 4, 26-42.

Goubert, L., Crombez, G., \& Van Damme, S. (2004). The role of neuroticism, pain catastrophizing and pain-related fear in vigilance to pain: a structural equations approach. Pain, 107(3), 234-241.

Horn, M. E., Alappattu, M. J., Gay, C. W., \& Bishop, M. (2014). Fear of severe pain mediates sex differences in pain sensitivity responses to thermal stimuli. Pain Research and Treatment, 2014, 897953. doi:10.1155/2014/897953 
John, O. P., \& Srivastava, S. (1999). The Big Five trait taxonomy: History, measurement, and theoretical perspectives. In Pervin, L. A. \& John, O. P. (Eds), Handbook of personality: Theory and research (pp. 102-138). New York, NY : Guilford.

Keogh, E., \& Asmundson, G. J. G. (2004). Negative affectivity, catastrophizing, and anxiety sensitivity. In Asmundson, G. J. G. Vlaeyen, J. W. S. \& Crombez, G. (Eds.), Understanding and treating fear of pain (pp. 91-115). New York: Oxford University press.

Kiecolt-Glaser, J. K., McGuire, L., Robles, T. F., \& Glaser, R. (2002). Emotions, morbidity, and mortality: new perspectives from psychoneuroimmunology. Annual Review of Psychology, 53, 83-107.

Kokkonen, M., \& Pulkkinen, L. (2001). Extraversion and Neuroticism as antecedents of emotion regulation and dysregulation in adulthood. European Journal of Personality, 15(6), 407-424.

Kumari, V., Ffytche, D. H., Das, M., Wilson, G. D., Goswami, S., \& Sharma, T. (2007). Neuroticism and brain responses to anticipatory fear. Behavioral Neuroscience, 121(4), 643-52.

Lilienfeld, S. O., Turner, S. M., \& Jacob, R. G. (1993). Anxiety sensitivity:an examination of theoretical and methodological issues. Advances in Behaviour Reserach and Therapy, $15,147-183$.

McCrae, R. R., Costa, P. T., Ostendorf, F., Angleitner, a, Hrebícková, M., Avia, M. D., ... Smith, P. B. (2000). Nature over nurture: temperament, personality, and life span development. Journal of Personality and Social Psychology, 78(1), 173-186.

McCrae, R. R., \& Terracciano, A. (2005). Personality profiles of cultures: aggregate personality traits. Journal of Personality and Social Psychology, 89(3), 407-425. 
Meulders, A., Vansteenwegen, D., \& Vlaeyen, J. W. S. (2012). Women, but not men, report increasingly more pain during repeated (un)predictable painful electrocutaneous stimulation: Evidence for mediation by fear of pain. Pain, 153(5), 1030-1041.

Molcho, M., Harel, Y., Pickett, W., Scheidt, P. C., Mazur, J., Overpeck, M. D., \& HBSC Violence and Injury Writing Group. (2006). The epidemiology of non-fatal injuries among 11-, 13- and 15-year old youth in 11 countries: findings from the 1998 WHOHBSC cross national survey. International Journal of Injury Control and Safety Promotion, 13(4), 205-211.

Muñoz Sastre, M. T., Albaret, M.-C., Maria Raich Escursell, R., \& Mullet, E. (2006). Fear of pain associated with medical procedures and illnesses. European Journal of Pain, 10(1), 57-66.

Norton, P. J., \& Asmundson, G. J. G. (2004). Anxiety sensitivity, fear, and avoidance behavior in headache pain. Pain, 111, 218-223.

Osman, A., Breitenstein, J. L., Barrios, F. X., Gutierrez, P. M., \& Kopper, B. a. (2002). The Fear of Pain Questionnaire-III: further reliability and validity with nonclinical samples. Journal of Behavioral Medicine, 25(2), 155-173.

Preacher, K. J., \& Hayes, A. F. (2008). Asymptotic and resampling strategies for assessing and comparing indirect effects in multiple mediator models. Behavior Research Methods, 40(3), 879-891.

Pytlik Zillig, L. M., Hemenover, S. H., \& Dienstbier, R. A. (2002). What do we assess when we assess a Big 5 trait? A content analysis of the affective, behavioral and cognitive processes represented in the Big 5 personality inventories. Personality and Social Psychology Bulletin, 28(6), 847-858.

Rachman, S. (1998). Anxiety. Psychological Press : Hove. 
Racine, M., Tousignant-Laflamme, Y., Kloda, L. A., Dion, D., Dupuis, G., \& Choinière, M. (2012). A systematic literature review of 10 years of research on sex/gender and experimental pain perception - part 1: are there really differences between women and men? Pain, 153(3), 602-618.

Reiss, S. (1991). Expectancy model of fear, anxiety, and panic. Clinical Psychology Review, $11,141-153$.

Riley, J. L., Robinson, M. E., Wise, E. A., Myers, C. D., \& Fillingim, R. B. (1998). Sex differences in the perception of noxious experimental stimuli: a meta-analysis. Pain, 74(2-3), 181-187.

Rokke, P. D., Fleming-Ficek, S., Siemens, N. M., \& Hegstad, H. J. (2004). Self-efficacy and choice of coping strategies for tolerating acute pain. Journal of Behavioral Medicine, 27(4), 343-360.

Rolland, J. P., Parker, W. D., \& Stumpf, H. (1998). A Psychometric Examination of the French Translations of NEO-PI-R and NEO-FFI. Journal of Personality Assessment, 71(2), 269-291.

Sanford, S. D., Kersh, B. C., Thorn, B. E., Rich, M. A., \& Ward, L. C. (2002). Psychosocial mediators of sex differences in pain responsivity. The Journal of Pain: Official Journal of the American Pain Society, 3(1), 58-64.

Scheidt, P. C., Harel, Y., Trumble, A. C., Jones, D. H., Overpeck, M. D., \& Bijur, P. E. (1995). The epidemiology of nonfatal injuries among US children and youth. American Journal of Public Health, 85(7), 932-938.

Smith, S. J. A., Keefe, F. J., Caldwell, D. S., Romano, J., \& Baucom, D. (2004). Gender differences in patient-spouse interactions: a sequential analysis of behavioral interactions in patients having osteoarthritic knee pain. Pain, 112(1-2), 183-187. 
Sorić, I., Penezić, Z., \& Burić, I. (2013). Big Five Personality Traits, Cognitive Appraisals and Emotion Regulation Strategies as Predictors of Achievement Emotions. Psychological Topics, 22(2), 325-349.

Sullivan, M., Bishop, S., \& Pivik, J. (1995). The Pain Catastrophizing Scale: Development and validation. Psychological Assessment, 7(4), 524-532.

Tan, G., Jensen, M. P., Robinson-Whelen, S., Thornby, J. I., \& Monga, T. (2002). Measuring control appraisals in chronic pain. The Journal of Pain, 3(5), 385-393.

Taylor, S. (1993). The structure of fundamental fears. Journal of Behaviour Therapy and Experimental Psychiatry, 24, 289-299.

Vancleef, L. M. G., Peters, M. L., Roelofs, J., \& Asmundson, G. J. G. (2006). Do fundamental fears differentially contribute to pain-related fear and pain catastrophizing? An evaluation of the sensitivity index. European Journal of Pain, 10, $527-536$.

Vecchione, M., Alessandri, G., Barbaranelli, C., \& Caprara, G. (2012). Gender differences in the Big Five personality development: A longitudinal investigation from late adolescence to emerging adulthood. Personality and Individual Differences, 53(6), $740-746$.

Vlaeyen, J. W., \& Linton, S. J. (2000). Fear-avoidance and its consequences in chronic musculoskeletal pain: a state of the art. Pain, 85(3), 317-332. 
Table 1. Means, standard deviations, sex difference $t$-tests, and correlations among the study variables $(n=229)$

\begin{tabular}{|c|c|c|c|c|c|c|c|c|c|}
\hline & \multicolumn{2}{|c|}{ Mean $(S D)$} & \multirow[t]{2}{*}{$t$} & \multirow[t]{2}{*}{1} & \multirow[t]{2}{*}{2} & \multirow[t]{2}{*}{3} & \multirow[t]{2}{*}{4} & \multirow[t]{2}{*}{5} & \multirow[t]{2}{*}{6} \\
\hline & Men & Women & & & & & & & \\
\hline 1. Neuroticism & $80.61(18.31)$ & $96.11(20.63)$ & $5.87 *$ & - & & & & & \\
\hline 2. Fear of severe pain & $6.01(2.18)$ & $6.82(1.89)$ & $3.01 *$ & $.25 * * *$ & - & & & & \\
\hline 3. Fear of minor pain & $1.79(1.45)$ & $2.32(1.73)$ & $2.42 *$ & $.16^{*}$ & $.37 * * *$ & - & & & \\
\hline 4. Fear of medical pain & $3.03(2.33)$ & $3.93(2.49)$ & $2.77^{*}$ & $.18 * *$ & $.33 * * *$ & $.41 * * *$ & - & & \\
\hline 5. Previous experiences with severe pain & $1.07(1.02)$ & $.73(.77)$ & $2.91 *$ & -.06 & -.13 & .06 & -.03 & - & \\
\hline 6. Previous experiences with minor pain & $4.66(.54)$ & $4.61(.56)$ & .64 & -.06 & .03 & $-.14 *$ & -.12 & .11 & - \\
\hline 7. Previous experiences with medical pain & $3.82(1.13)$ & $3.56(1.07)$ & 1.82 & -.07 & -.07 & .02 & $-.14 *$ & .09 & .11 \\
\hline
\end{tabular}

Note: $* p<.05, * * \mathrm{p}<.01, * * * \mathrm{p}<.001$ 
Table 2. Direct effects of the studied variables on fear of severe pain.

\begin{tabular}{|c|c|c|c|c|c|}
\hline & \multicolumn{2}{|c|}{ Direct effect of sex to mediators } & \multicolumn{2}{|c|}{ Direct effect of mediators on fear of severe pain } & \multirow[t]{2}{*}{ Confidence interval } \\
\hline & $\mathrm{B}$ & SE & B & $\mathrm{SE}$ & \\
\hline Anxiety & $4.37 *$ & .74 & $.11 *$ & .03 & $.21-.89$ \\
\hline Anger hostility & $1.81^{*}$ & .65 & .02 & .03 & $-.08-.21$ \\
\hline Depression & $2.96^{*}$ & .66 & -.03 & .04 & $-.38-.11$ \\
\hline Self-consciousness & $2.05^{*}$ & .60 & -.01 & .04 & $-.15-.15$ \\
\hline Impulsiveness & .46 & .60 & -.04 & .03 & $-.14-.02$ \\
\hline Vulnerability & $3.77 *$ & .61 & .03 & .04 & $-.13-.46$ \\
\hline
\end{tabular}


Table 3 Direct effects of the studied variables on fear of medical pain.

\begin{tabular}{|c|c|c|c|c|c|}
\hline & \multicolumn{2}{|c|}{ Direct effect of sex to mediators } & \multicolumn{2}{|c|}{ Direct effect of mediators on fear of severe pain } & \multirow[t]{2}{*}{ Confidence interval } \\
\hline & $\mathrm{B}$ & SE & $\mathrm{B}$ & SE & \\
\hline Anxiety & $4.39 *$ & .73 & $.08^{*}$ & .04 & $.08-.67$ \\
\hline Anger hostility & $1.77 *$ & .64 & .03 & .04 & $-.05-.23$ \\
\hline Depression & $2.75^{*}$ & .65 & -.02 & .05 & $-.29-.17$ \\
\hline Self-consciousness & $2.15^{*}$ & 60 & -.05 & .04 & $-.30-.02$ \\
\hline Impulsiveness & .37 & .60 & .03 & .04 & $-.02-.11$ \\
\hline Vulnerability & $3.85^{*}$ & .61 & .01 & .05 & $-.31-.34$ \\
\hline
\end{tabular}



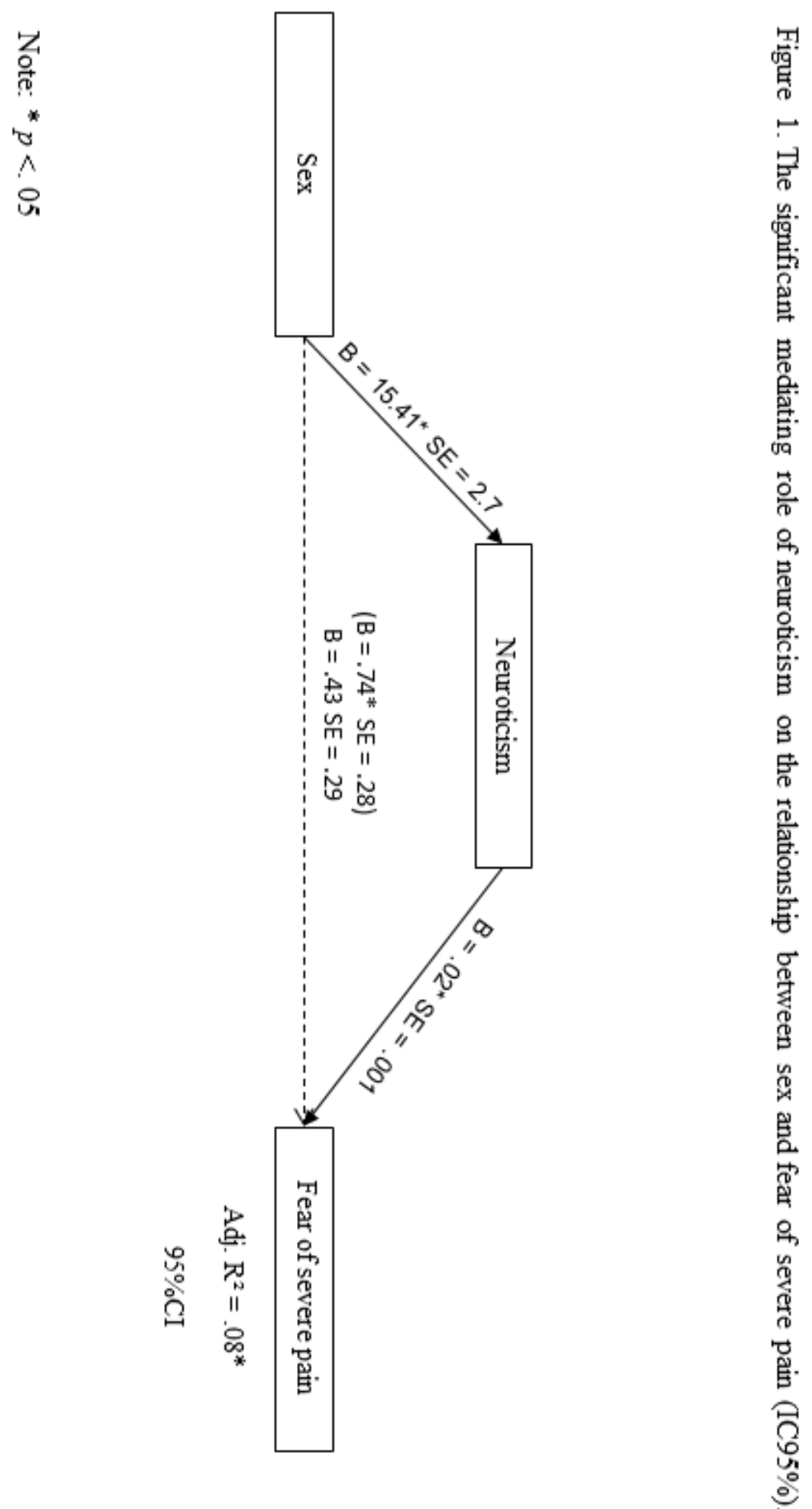
2
0
0
0
0
0
0
0
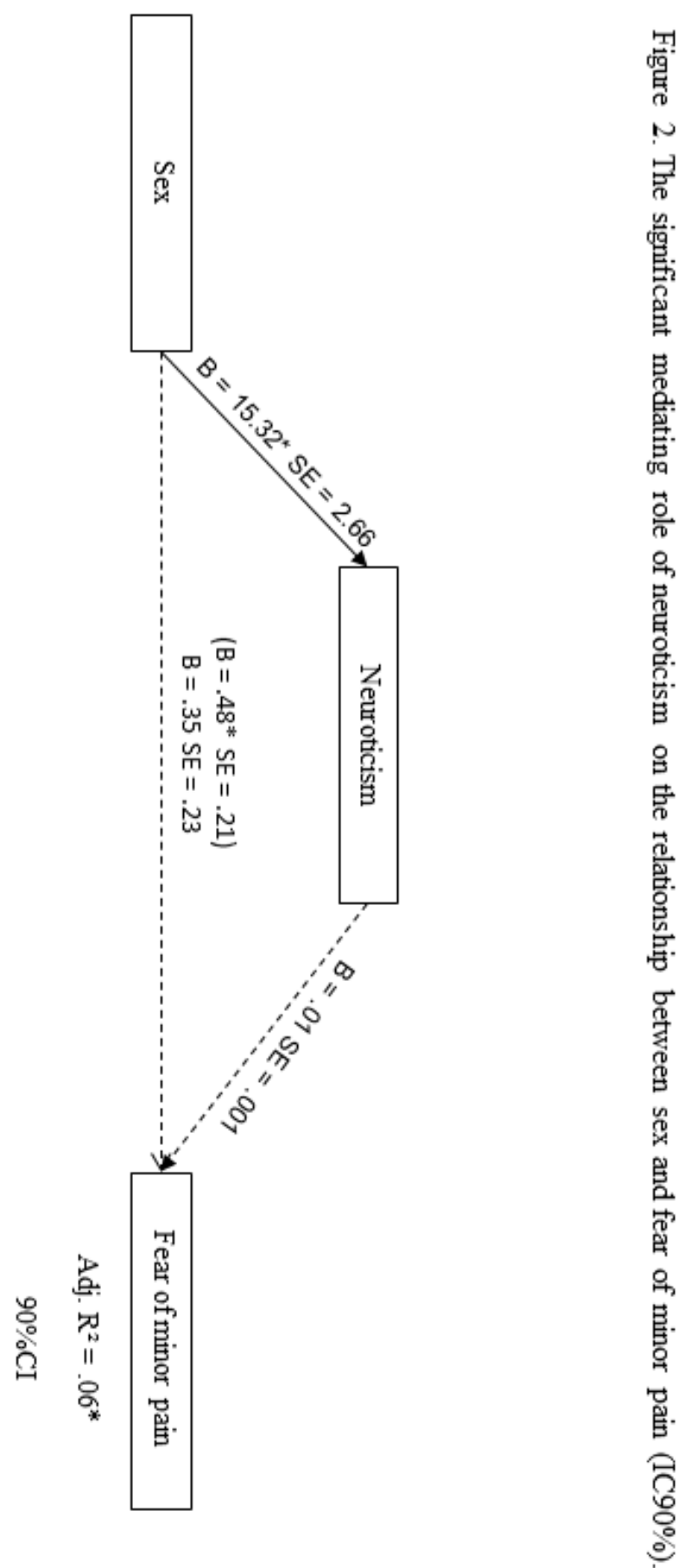

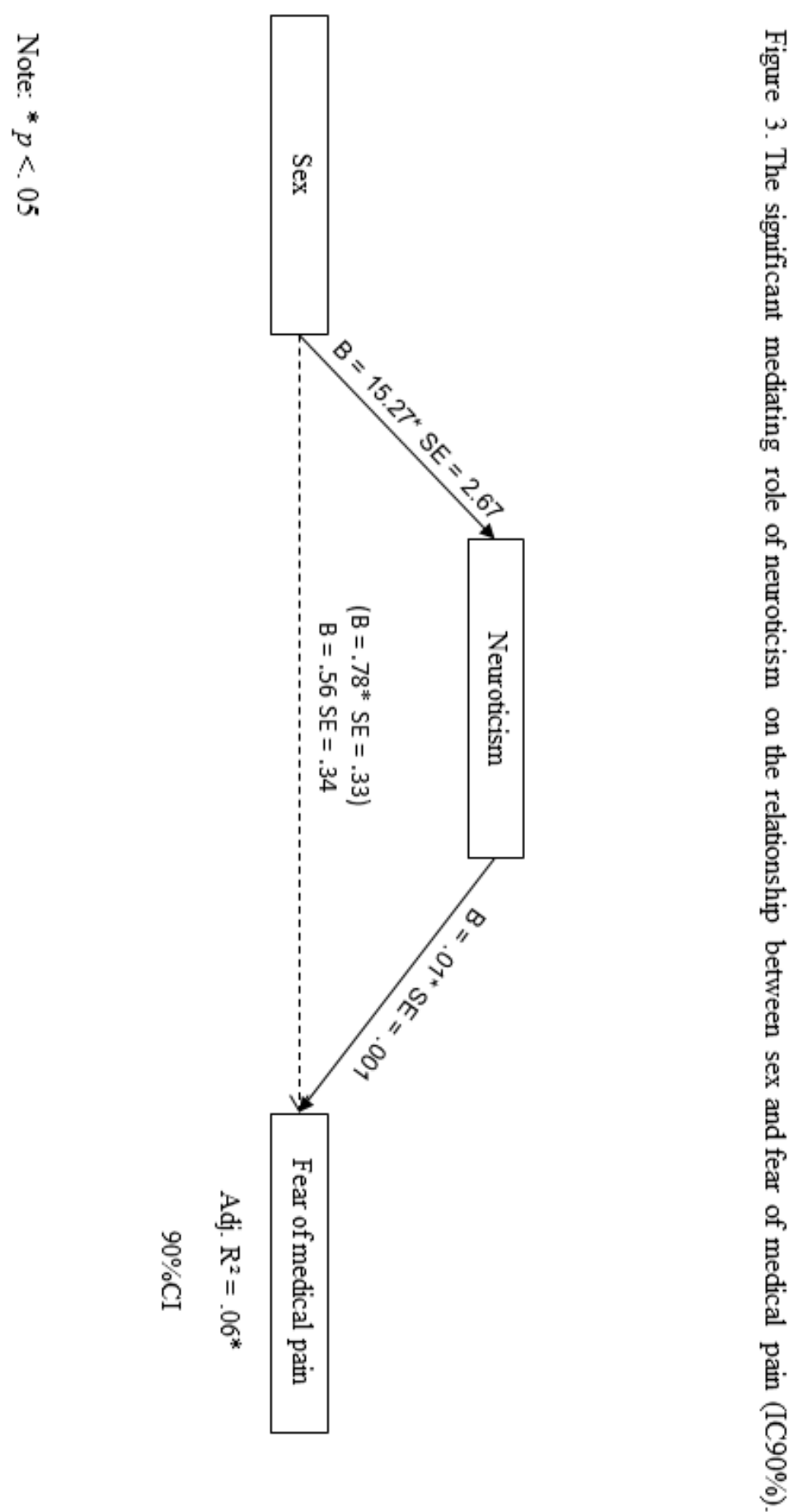
My co-authors and I have no financial or other relationships that might lead to a conflict of interest and all authors stated hereby contributed substantially to experimental design, experimental assessment, data and statistical analyses as well as preparation of the manuscript. 